\title{
DNA donor rights affirmed
}

\section{NIH committee urges that genome study subjects be told of medically relevant results.}

\section{BY ERIKA CHECK HAYDEN}

$\mathrm{I}$ $\mathrm{t}$ is a familiar scenario in genetic research: a subject's DNA is collected for one study, deposited in a database or biobank and then analysed by other researchers for separate studies. But what happens when a later study stumbles on something that could be of significance for the donor, such as an allele for familial hypercholesterolaemia - a treatable genetic disorder that causes progressive atherosclerosis - or some other health-related variation? Do researchers conducting secondary studies and biobanks have a duty to share such revelations with the original research subjects?

They do, when possible, according to a detailed consensus statement from a working group funded by the US National Institutes of Health (NIH) in Bethesda, Maryland, and published this week (S. M. Wolf et al. Gen. Med. http://dx.doi.org/10.1038/ gim.2012.23; 2012). The statement's 26 signatories consulted dozens of other researchers and biobank managers over a two-year period. They conclude that biobanks "shoulder significant responsibility" for addressing how to deal with 'incidental findings' - those research results that could have medical consequences for the donors of genetic material.

Genetics researchers are divided on the matter of incidental findings. Conventional research ethics holds that participants should not be told of their individual results, to keep them from expecting to benefit personally from the study. What's more, reporting such findings can be a logistical challenge because many studies strip identifying information from donated samples. But, increasingly, geneticists are embracing the idea that research participants have a right to know of any unwelcome surprises in their genome. "If we really believe this is medically valuable and useful data, then we have to act on it," says Leslie Biesecker of the US National Human Genome Research Institute in Bethesda, who contributed to the discussions that led up to the consensus statement but is not a signatory. recommends that each biobank sets up a committee to oversee the return of results and also that a single central advisory body be created that would foster consistency among biobank research systems. Wolf led a previous NIH working group that in 2008 published recommendations proposing that primary researchers - those responsible for collecting data - should report some incidental findings back to research participants (S. M. Wolf et al. J. Law Med. Ethics 36, 219-248; 2008).

But some researchers warn that keeping track of incidental results and re-identifying participants so that they can be informed could prove costly and pose ethical and legal difficulties. "It's unfortunate that the authors of the consensus statement didn't discuss the cost implications of what they're proposing, because what they have in mind is going to be expensive and difficult, particularly at a time when funding success is as low as it's ever been," says Ellen
The need to establish policies for the return of results has grown with the proliferation of whole-genome sequencing, says James Evans, editor-in-chief of Genetics in Medicine, which is publishing an entire issue on the return of results in genetic research, along with the consensus statement.

In the past, says Evans, medically significant incidental findings were an exception in genetic studies, but "when you do wholegenome sequencing you will regularly come up with findings that have some medical import". Yet less than half of US biobanks return results to participants, according to a study done for the working group by Mao Thao of the University of Minnesota in Twin Cities and colleagues. The working group, coordinated by Susan Wolf of the University of Minnesota Law School in Minneapolis, urges biobanks to take the lead in changing that ethos. The group Wright Clayton, a paediatrician and lawyer at the Center for Biomedical Ethics and Society at Vanderbilt University in Nashville, Tennessee.

Wolf counters that some biobanks already do return results, so it does not need to be prohibitively costly or difficult. For instance, Biesecker runs a study called ClinSeq, which has enrolled around 900 people whose exomes (the protein-coding part of the genome) are being sequenced. The participants are told about any findings that could have implications for their health care. Biesecker says that there is an increasing tension in the field between studies such as his that underscore the usefulness of genetic medicine and an assumption that it is too costly and difficult to use the results of such studies to help improve patients' lives. "I don't think, as a field, that we can continue to say both things at the same time," Biesecker says. a SEE EDITORIAL P.373

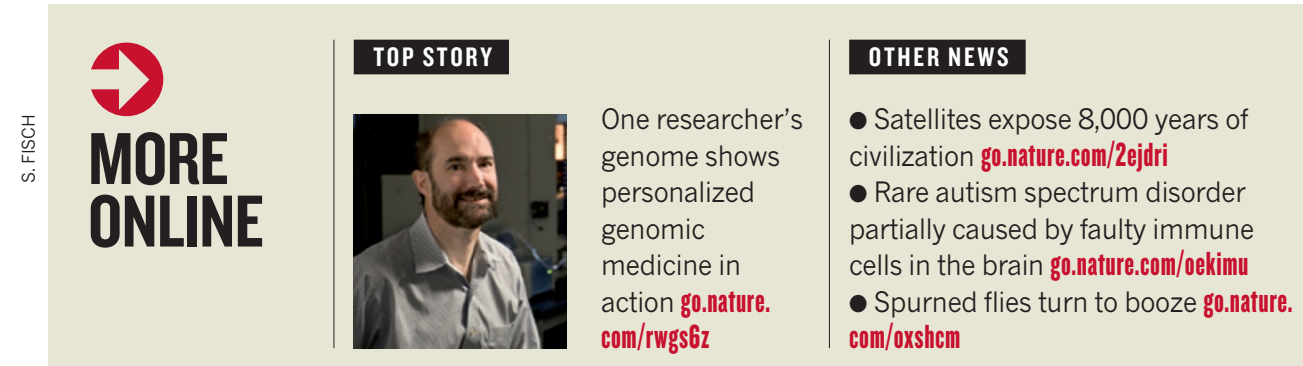

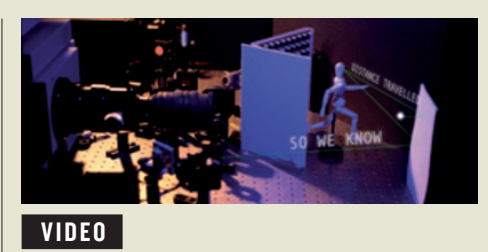

The laser that can see around corners go.nature.com/is4lfx 